\title{
Physical properties and microstructure of fuel pellet made from parts of Para-rubber, She Oak and Cajuput trees
}

\author{
Wassachol Wattana ${ }^{1 *}$, Warunee Bawornkiatkaew ${ }^{2}$, and Anupong Ponpijit ${ }^{2}$ \\ ${ }^{1}$ KMITL Prince of Chumphon Campus, Mechanical Engineering Department, 17/1 M.6 Chumkho \\ Pathiu Chumphon, Thailand \\ ${ }^{2}$ National Metal and Materials Technology Center (MTEC), 114 Thailand Science Park, \\ Phahonyothin Road, Khlong Nueng, Khlong Luang, Pathum Thani, Thailand.
}

\begin{abstract}
There are plenty of biomass resources in Thailand such as agricultural residues from plantations and industrial or woody processes. Biomass in the form of a pellet has more energy density than the original form moreover it is easier to handle and has a higher strength. This study selected woody parts from commonly found trees in Southern Thailand, fuel pellets were made to examine the physical properties and microstructure. Para-rubber (Hevea brasiliensis Muell. Arg.) sawdust and the branches and leaves of She Oak (Casuarina Equisetifolia) and the Cajuput tree (Melaleuca Cajuputi) were collected from the local area to make pellets by a single unit pellet mill at $130 \mathrm{oC}$ and $450 \mathrm{psi}$ of compression temperature and pressure, respectively. The physical properties were characterized via pellet density, moisture content, heating value and compressive strength. Moreover, the microstructure of cross section area of pellet samples from the scanning electron microscope (SEM) pictures were proposed to observe the bonding mechanism. The results show that the different raw material provided different properties. The highest pellet strength, density and heating value was achieved from Cajuput leaves.
\end{abstract}

\section{Introduction}

Biomass pellets have been an interest as renewable solid fuel which is uncomplicated to produce and be utilized. Cylindrical pellets are produced from the densification process, which is the physical conversion technique to improve the quality of raw materials. Solid fuel in pellet form, provides high energy density according to the increase of pellet and bulk densities which cause reducing to the handling, storage and transportation costs [1]. Although, there are many varieties of biomass resources that have been interesting to use as raw material to produce pellets. However, wood pellets is the most commonly used in the world [2]. Monedero E et al. [3] was studying the physical-chemical properties in proportion of Poplar and Pine sawdust to produce pellets whilst corresponding to ENPlus qualities. The pelletization process and composition of raw material that effect on the pellets quality was

\footnotetext{
* Corresponding author: wassachol.wa@kmitl.ac.th
} 
evaluated. They found that, the use of blends of Poplar and Pine sawdust can enhance the Poplar pellet quality. The investigation of pelletization process on fuel conversion of Pine wood pellet combustion was proposed by K. Biswas et al. [4]. Combustion behaviours were examined by a laboratory-scale furnace, and moreover the morphology of pellets examined by the scanning electron microscope (SEM).

She Oak (Casuarina Equisetifolia) and Cajuput tree (Melaleuca Cajuputi) are common trees of southern Thailand which tend to become extinct because of the decrease of its utilization. Then, the objective of this study was to assess the utilization potential of the parts of She Oak and Cajuput trees as raw materials of solid fuel pellet production. The physical properties and microstructure of pellets made from the branches and leaves of the She Oak and Cajuput tree were examined.

\section{Material and methods}

\subsection{Material}

The five raw materials in this study were collected from the local area. The Para-rubber sawdust was received from local pellet manufacturers. The branches and leaves of Cajuput and She Oak trees (as seen in figure 1) from KMITL Prince of Chumphon Campus farm and near the beach of Ao Bo Mao bay, respectively, were harvested and then were cleaned, and dried in sunlight for three days. Before pelleting, all raw materials were ground down and sieved down to size below $1 \mathrm{~mm}$.

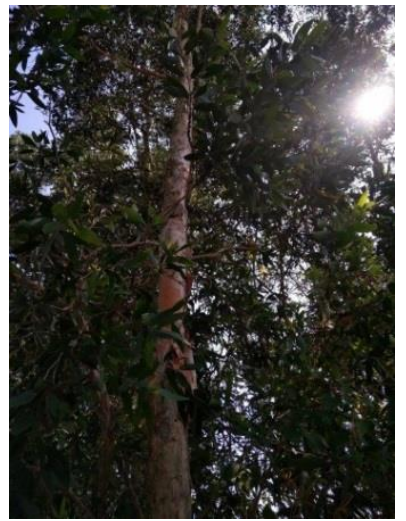

(a)

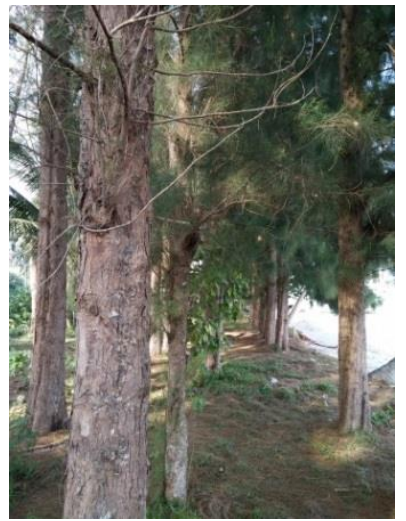

(b)

Fig. 1. Cajuput tree (a) and She Oak tree (b) in the local area.

\subsection{Method}

The fuel pellets of three samples of each condition were produced by a single pelletizer consisting of die and plug with a $10 \mathrm{~mm}$ diameter hole. The appropriate condition of pellet production from our pelletizer was studied first. Then, the compression temperature and pressure of this study was $130^{\circ} \mathrm{C}$ and $450 \mathrm{psi}$, respectively. The ground raw materials, around 5 grams, was placed into dye, then the die was heated to reach the set temperature by heating the wrap outside of the die surface and the plug compressed the raw material inside the dye to target pressure and held for $4 \mathrm{~min}$. The compressive strength of pellet samples were calculated from the maximum force at the pellet broken which measured from a Texture 
Analyzer (LLOYD Instruments, TA Plus) by placing the pellet sample in a horizontal direction between flat plates in which the top plate was lowered at the constant rate of 0.5 $\mathrm{mm} / \mathrm{s}$ until the sample was broken. The maximum force was recorded and the compressive strength was calculated as described in literature [5]. The pellet density was calculated from the ratio of mass and cylindrical volume of pellet samples. The moisture content of the pellets were determined by drying in a hot air oven at $105^{\circ} \mathrm{C}$ for $24 \mathrm{hrs}$. The higher heating value was measured by bomb calorimeter. The SEM (Hitachi, S3400N) was used to examine the microstructure of the pellet samples produced.

\section{Results and discussion}

The pellet production of the five raw materials composed of Para-rubber sawdust (PS), She Oak branch (SB), She Oak leaves (SL), Cajuput branch (CB), and Cajuput leaves (CL) were examined in the way of physical properties and structural characteristics. The physical properties and higher heating value were shown in Table 1 below.

Table 1. Physical properties of each type of raw material pellets.

\begin{tabular}{|c|c|c|c|c|c|}
\hline Properties & PS & SB & SL & CB & CL \\
\hline Higher Heating Value, MJ/kg & 4249.70 & 4197.19 & 4650.75 & 4418.19 & 4815.24 \\
\hline Compressive Strength, MPa & 1.79 & 1.64 & 3.09 & 4.61 & 4.14 \\
\hline Moisture Content, \% & 6.02 & 5.17 & 6.33 & 5.46 & 6.92 \\
\hline Pellet Density, $\mathrm{kg} / \mathrm{m}^{3}$ & 1080.42 & 943.41 & 1077.47 & 967.80 & 1106.33 \\
\hline
\end{tabular}

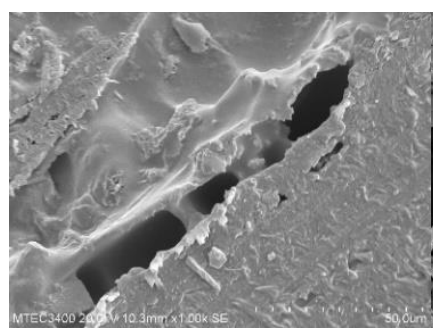

(a)

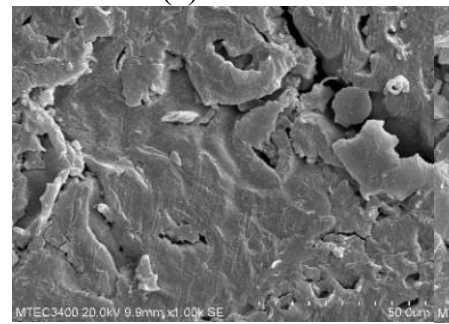

(d)

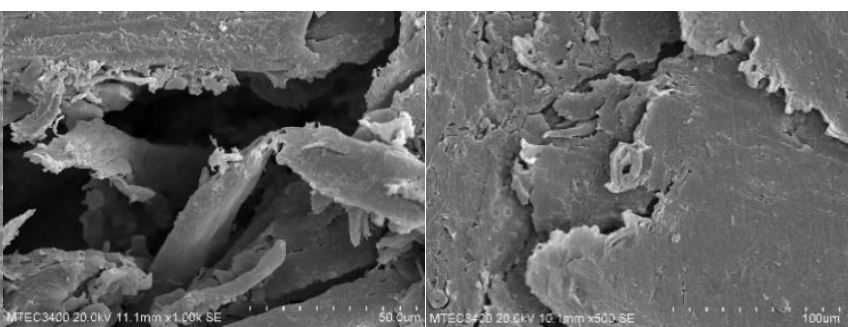

(b)

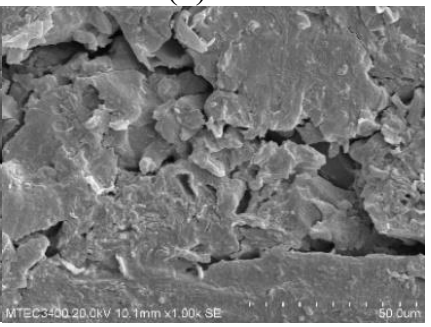

(e)

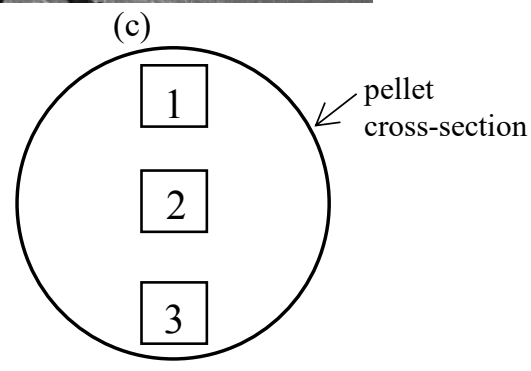

Fig. 2. SEM of (a) SB, (b) PS, (c) SL, (d) CL and (e) CB at the center position (position 2). 


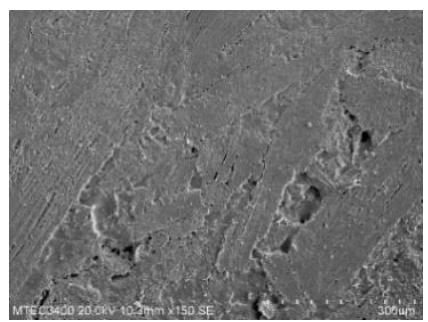

(a)

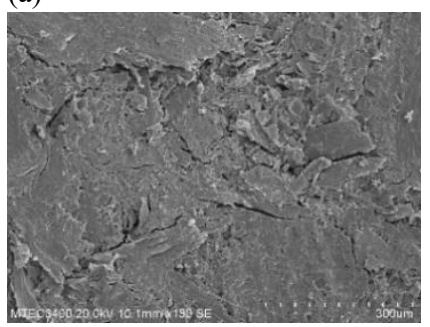

(b)
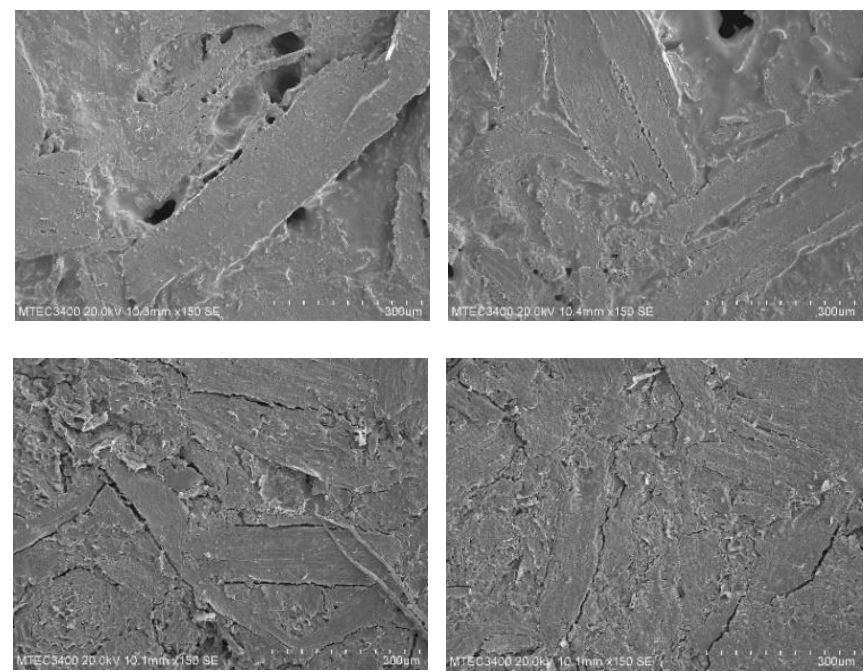

Fig. 3. SEM of (a) SB and (b) CB at position 1 (left), 2 (middle) and 3 (right).

The pellet from CL provided the highest energy which corresponds to the Cajuput leaves is composing of essential oils [6]. The moisture contents are not much different among the 5 types of raw materials, however, the CL provided the highest value because of its green leaves, the raw material has more water content than SL raw material. The CL pellet provided the highest pellet density that corresponds to the highest heating value which it provided. Moreover, the high moisture content of CL is the important variable of densification process that might improve the binding mechanisms [7]. The compressive strength is the property that is related to the microstructure of the pellet after the densification process. Although, the CB pellet provided the most strength among the five pellet conditions, however the CL pellet showed good strength character too.

Figure 2 shows the SEM picture of the microstructure of the five different fuel pellet conditions at the center position of pellet cross-sections. It was found that the SB pellet has the most poor adhesion than the other raw materials. Figure 3 shows a SEM picture of the best and worst pellet conditions with regards to the strength quality at the side and center of the pellet cross-section (see Figure 2). It was found that SB pellet has more pores or voids than the $\mathrm{CB}$ pellet. Moreover, the $\mathrm{CB}$ pellet provided similar structures at each position more than in the case of the SB pellet. The microstructure of pellets that were examined via SEM pictures to show the characteristics corresponding to the result of the maximum compressive strength of pellet samples, as shown in Table 1. The more voids mean the longer distance between particles, this causes less attraction force which leads to low density and strength [8].

\section{Conclusions}

The fuel pellets made from branches and leaves of the She Oak (SB and SL) and Cajuput (CB and CL) trees in southern Thailand and Para-rubber sawdust (PS) were evaluated the utilization potential through the physical properties and microstructure. The different raw material provided different properties according to chemical composition. In this study, the Cajuput leaves are more preferred to be used as raw materials for fuel pellet production than 
the She Oak. The highest pellet strength, density and higher heating value were achieved from CL.

This work was supported by Higher Education Research Promotion (HERP) and King Mongkut's Institute of Technology Ladkrabang (KMITL). In addition, the authors are very grateful to National Metal and Materials Technology Center (MTEC) for SEM equipment and facilities support.

\section{References}

1. H. Hartmann and V. Lenz, biomass energy heat provision in modern small-scale system Encyclopedia of Sustainability Science and Technology, edited by RA. Myer (Springer, New York, 2012)

2. A. Pirraglia, R. Gonzalea, and D. Saloni, BioResources 5, 2374 (2010)

3. E. Monedero, H. Portero, and M. Lapuerta, Fuel Processing Technology 132, 15 (2015)

4. K. Biswas, M. Rudolfsson, M. Broström, and K. Umeki, Applied Energy 119, 79 (2014)

5. A. Bazargan, L. Rough, and G. McKay, Biomass and Bioenergy 70, 489 (2014)

6. A. Hanif, H. Juahir, F. Lananan, A. Kamarudin, G. Adiana, A. Azemin, and I. Yusra, Journal of Fundamental and Applied Sciences 10(1S), 135 (2018)

7. S. Tumuluru, T. Wright, R. Hess, and L. Kenney, Biofuels Bioprduct\&Biorefining 5, 683 (2011)

8. L. Schineberger, Understanding Adhesives (Hitchcock Publishing Co, IL,USA, 1971) 